\title{
Informatização da vida e controle da existência
}

\section{Informatization of life and control of existence}

Resumo: Pretende-se levantar questões sobre a expansão das tecnologias da informática no contemporâneo e alguns de seus efeitos, em especial, no que se refere aos amplos sentidos da educação. Apontando para a sociedade de controle globalizado e para a "compressão tempo-espaço", problematiza-se como o processo de tratamento das informações, por meio de máquinas eletrônicas, produz modos de existência, vetores de subjetivação. Na atualidade, tal controle vem se exercendo através da proliferação de sofisticados bancos de dados, disponíveis em rede em escala planetária. São inegáveis as facilidades trazidas por essas novas tecnologias e a rapidez com que se coletam e processam informações. No entanto, é preciso destacar que tais dispositivos não constroem conhecimento. Tal concepção vem sendo caracterizada como "democratização do acesso à informação", tudo muito isento, asséptico, neutro e objetivo. A facilidade com que se trocam informações e a instantaneidade dos sistemas de comunicação instauram em nós tais evidências naturalizadas. Por isso, mais do que nunca, necessitamos de uma ética afirmativa que se contraponha, como via de escape, à moral negativa da filantropia, ao assistencialismo e à punibilidade tão arraigados em nossas subjetividades contemporâneas.

Palavras-chave: Controle. Tecnologias da informática. Processo de subjetivação. Produção de conhecimento. Ética.

Abstract: This article intends to raise issues on the expansion of informatics technologies in contemporary times and some of its effects, specially, in concern of the broad senses of education. Pointing to the society of global control and to the "time-space compression", it raises issues on how the treatment process of information, by means of electronic apparel, produces ways of existence, vectors of subjectivity production. Currently, such control is being done through the proliferation of sophisticated data banks, available in planetary scale. The conveniences offered by these technologies and the speed in which information is gathered is undeniable. However, it is necessary to point out that such mechanisms do not consist in the construction of knowledge. This notion is being portrayed as "information access democratization", all very unbiased, aseptic, neutral and objective. The easy way of exchanging information and the real-time speed of communication systems construct, before us, naturalized evidence. For this, more than ever, the need for affirmative ethics that oppose, as an escape, the negative morals of philanthropy, the empty-assistance politics and the punish-ability that are so entrenched in the contemporary subjectivities.

Keywords: Control. Informatics Technologies. Subjectivity production processes. Knowledge production. Ethics.

NASCIMENTO, Maria Lívia do; LOBO, Lilia; COIMBRA, Cecília Maria Bouças. Informatização da vida e controle da existência. Informática na Educação: teoria \& prática, Porto Alegre, v. 11, n. 1, p.69-78, jan./jun. 2009.

\author{
Maria Lívia do Nascimento \\ Lilia Lobo \\ Cecília Maria Bouças Coimbra \\ Universidade Federal Fluminense, Niterói, Brasil
}

\section{I ntrodução}

“Mundo hoje: oceano infinito, agitado por ondas turbilhonares - fluxos variáveis sem totalização possível, sem fronteiras estáveis, em constantes rearranjos [...]" (ROLNIK, 1998, p. 1).

N

osso propósito aqui é levantar algumas questões acerca da expansão dos dispositivos da informática e alguns de seus efeitos nos processos de subjetivação contemporâneos, que incluem as práticas da vida diária, da educação, da arte, do controle das populações, dentre outras.

Para tanto, tomamos como discussão inicial o pensamento de Harvey (1993), quando ele nos fala da "sociedade de acumulação flexível de capital" e do que chama "compressão tempo-espaço". De acordo com o autor, no contemporâneo, acelera-se o tempo de giro na produção e no consumo: aperfeiçoam-se e tornam-se velozes as comunicações, os fluxos de informações, as técnicas de distribuição e circulação de mercadorias. Bancos eletrônicos, dinheiro de plástico, mercados financeiros e comércio computadorizado produzem profunda compressão no tempo e no espaço, tanto nos momentos de alta, quanto na crise que hoje nos assola em escala planetária.

Nessa sociedade de acumulação flexível de capital enfatizam-se os modos de existência 
onde se afirmam os valores e as virtudes da instantaneidade, da descartabilidade, do planejamento e ganhos de curto prazo, da capacidade de se movimentar com rapidez em respostas às mudanças do mercado ou do planejamento, da perda de um sentido de futuro, onde tudo vai se tornando instantâneo, descartável, fragmentado e obsoleto.

As opiniões são produzidas e manipuladas através da construção de novos sistemas de signos e imagens que se tornam mercadorias a serem comercializadas. Por outro lado, junto a esta produção de imagens efêmeras constrói-se, para o público em geral, a valorização de imagens estáveis cercadas de autoridade e poder: o ideal de uma estabilidade democrática, a permanência e o aperfeiçoamento de suas instituições, uma ordem social baseada na normalização e na punibilidade.

Além do tempo, também o espaço se comprime, diminui e se torna ínfimo. Tempo e espaço vão desaparecendo enquanto dimensões significativas para nós, os humanos. Hoje, entrelaçam-se no mesmo espaço e no mesmo tempo diferentes mundos, diferentes experiências que, entretanto, correm o constante risco de serem homogeneizados através dos processos de subjetivação dominantes: tudo o que é produzido, é divulgado, distribuído, comercializado e rapidamente consumido.

Algumas questões referentes a essa compressão tempo espaço podem ser analisadas a partir do paradigma da informática. O processo de tratamento da informação por meio de máquinas eletrônicas - computadores produziu um impacto nos modos de existência, sobretudo com o advento das redes de computadores interligados.

\footnotetext{
A informática, as telecomunicações e as biotecnologias representam três áreas fundamentais da tecnociência contemporânea. Recorrendo ao instrumental teórico foucaultiano, podemos afirmar que tais saberes - enquistados em claras relações de poder - estão contribuindo fortemente para a produção dos corpos e das almas deste início de século, apresentando um conjunto de promessas, temores, sonhos e realizações inteiramente novos (SIBILIA, 2002, p. 11, grifos da autora).
}

Importante lembrar que outras formas de controle emergiram no começo do processo de industrialização no Brasil. Margareth Rago (1987), ao descrever o cotidiano do trabalho fabril no começo do século $X X$, indica técnicas coercitivas para a modelização de "corpos dóceis" (FOUCAULT, 1986) adaptados à produção e da extração da mais valia desta força de trabalho. Trata-se da ridicularização pela exposição, nas fábricas, de fotos dos operários indesejáveis:

[...] da variação nos salários, da intimidação pessoal, remuneração extremamente baixa, das 'listas negras', identificação policial nos livretes, [...] pelos quais os empresários e a polícia possuem informações minuciosas sobre a história pessoal e profissional do trabalhador [...] (RAGO, 1987, p. 26).

Com o tempo, a vigilância do poder será aos poucos mascarada e o panoptismo industrial substituído pelo controle técnico e científico da organização do trabalho, e outras "listas negras" informatizadas.

Se houve uma neutralização das rebeldias políticas dos trabalhadores, que o capitalismo capturou para minimizar os transtornos do absenteísmo, da destruição das máquinas, dos distúrbios nas cidades, isto se deu, dentre outras práticas, com a fundação dos sindicatos. Houve, porém, uma outra neutralização, muito mais sutil, operada pelo capitalismo no século $X X$ que vem transformando a velocidade tecnológica em ameaça de tragédia global: o aquecimento do planeta, uma superpopulação em estado de miséria, o medo generalizado da insegurança. Tudo isto transmutado num estilo de vida - desde que se acolha de bom grado a velocidade frenética, e o controle informatizado como medida de segurança - e assim todos os nossos problemas acabarão! A nova carteira de identidade ${ }^{1}$ que nos espera para os próximos anos - exigência da desgastada cidadania - contendo em chips absolutamente todos os dados individuais, é uma prova de que jamais poderemos passar despercebidos!

Nesse contexto, emergem subjetividades

\footnotetext{
${ }^{1}$ A partir de 2009 a carteira de identidade passará a ser chamada de RIC (Registro de Identidade Civil). Ela terá informações como a cor da pele, altura e peso. As informações digitais serão escaneadas e enviadas para um banco de dados do Instituto Nacional de I dentificação da Polícia Federal, alimentando o Sistema Automático de I dentificação de Impressões Digitais. O novo documento terá itens de segurança como dispositivo anti-escaner, imagens ocultas e palavras impressas com tinta invisível, fotografia e impressão digital a laser. Possuirá, também, um chip capaz de armazenar informações trabalhistas, previdenciárias e criminais.
} 
adaptadas a este paradigma, trazendo novas sensações, outras lógicas, moldagens de corpos que configuram os modos de existência, como também tecnologias sociais de controle. No contemporâneo tal controle vem se exercendo através da proliferação de sofisticados bancos de dados, agora disponíveis em rede. Com isso, se fortalece o chamado Estado Penal punitivo repressivo e a política de tolerância zero onde todos passam a ser criminalizados - em especial a pobreza e alguns movimentos sociais.

Wacquant (2002) aponta que na justiça dos EUA, além do altíssimo número de encarcerados, proliferam-se penas ditas intermediárias e ou alternativas, o policiamento intensivo, a escuta telefônica e os bancos de dados criminais em rede. Desde 1997, por exemplo, no estado de Illinois, há o livre acesso às fichas de todos os detentos atuais e antigos.

Com alguns toques no mouse, qualquer pessoa, sem nenhuma justificativa e sem qualquer controle, pode acessar a sinalética de todos os prisioneiros do Estado - nome, sobrenome, data e local de nascimento, número da previdência social (normalmente mantido em segredo), 'raça', altura e peso, sinais distintivos os mais íntimos, ('descrição de cada marca, cicatriz, tatuagem, incluindo a descrição física e a localização no corpo do detento') - como também um resumo de sua ficha policial com a enumeração de todas as suas condenações (natureza, categoria e número de infrações, algumas de vinte ou trinta anos antes, e local do julgamento). Assim, qualquer um pode saber quando e onde um detento foi preso, a data prevista (ou efetiva) de sua saída e de sua eventual libertação (WACQAUNT, 2002, p. 23).

Em nome da transparência e da democracia os EUA vêm colocando, desde os anos de 1970, todos os seus arquivos judiciários à disposição do público. Orientado pela Law Enforcement Administration Agency, órgão federal que luta contra a criminalidade, os Estados Unidos criaram bancos de dados centralizados e informatizados que, desde aquele período, vêm se irradiando pelo país inteiro. Não somente têm acesso a esses bancos as administrações públicas, mas também quaisquer pessoas e organizações privadas. Tais bancos são freqüentemente consultados pelos empregadores, por exemplo, no sentido de impedir que algum ex-presidiário se candidate a um emprego.

Quanto aos jovens, da mesma forma, há também bancos de dados eletrônicos sobre a localização de delinqüentes atuais e/ou suspeitos em potencial. A que têm servido tais fichas tão competentemente descritivas? No caso dos jovens, para mapear os locais por eles freqüentados, apontando a periculosidade desses territórios e de seus moradores. Serve, também para orientar a polícia em suas diligências e justificar suas práticas violentas, repressivas e exterminadoras.

Na França, em 1o de julho de 2008, foi publicado um decreto que autoriza o fichamento pela polícia de jovens a partir de 13 anos de idade. Tal decreto estabelece que para esses adolescentes - individualmente ou em grupos - "suscetíveis de prejudicar a ordem pública" serão preventivamente registrados nos arquivos policiais através de vários dados como endereço, telefone, e-mail, características físicas e de comportamento².

No Brasil, podemos também encontrar práticas de governo da vida onde o paradigma da informática ocupa um lugar central. Apontamos aqui, duas situações onde a aliança entre tecnologia de rede e vigilância estabelece uma combinação perigosa. O Programa Delegacia Legal, implementado no Rio de Janeiro a partir de 1999, coloca as delegacias como estabelecimentos de prestação de serviços à comunidade, e nessa função, valorizam a assepsia social. Um exemplo pode ser vislumbrado

[...] quando, à noite, os moradores de rua que procuram os abrigos públicos são obrigados a se dirigir às delegacias para receberem um encaminhamento assinado pelo delegado de plantão e pelo psicólogo ou assistente social [...] (RODRIGUES, 2008, p. 70).

Nesse momento, são rastreadas, via rede, informações a respeito da pessoa que busca o encaminhamento, assim como, são armazenados novos dados em sua ficha. Dessa forma, a simples busca de um local para passar a noite, pode ter efeitos desastrosos para aqueles que

\footnotetext{
2 “A medida visa a catalogar os jovens envolvidos em casos de violência urbana especialmente os que participam dos 'emeutes' (revoltas) nas periferias de Paris. Antes do decreto, os menores de idade só poderiam ser fichados se cometessem algum crime. O cumprimento da norma, denominada Edvige-Exploração Documental e Valorização da Informação Geral - é efetuado pela direção Central de Segurança Pública, órgão que controla a violência urbana e os conflitos sociais, além de realizar a contagem de manifestantes." (JARDIM, 2008).
} 
tenham, ou venham a ter, "algum débito com a justiça".

Um outro exemplo que podemos evocar é o SIPIA (Sistema de informação para a Infância e Adolescência) que arquiva, de forma permanente, as violações de direitos infanto-juvenis. Tal banco de dados, que pode servir de controle da vida de um determinado tipo de população, é alimentado pela informatização da ação dos conselhos tutelares, e faz parte da rede nacional de segurança pública do Ministério da Justiça. Para Martins e Ferreri (2004) o SIPIA “[...] constitui-se como mais um passo no governamento instituído da assistência à infância" (p. 206), prática que denominam "governamento on line".

O SIPIA assume todos os quesitos para a reflexão da governamentalidade; seu propósito de evidenciar carências da realidade político-assistencial dos municípios, e com isso dinamizar ações de caráter resolutivo, coloca-o dentro do conjunto de dispositivos governamentais de disposição de coisas, na medida em que isso represente visibilidades para a ação do o poder. [...] A sua filiação a sistemas de segurança caracteriza-o de forma ainda mais completa na definição de instrumento/tática de governamento, com traços policiais mais convencionais, no sentido que Foucault (1993) concebe o problema da governamentalidade (MARTINS; FERRERI, 2004, p. 216).

O registro nessas diferentes redes de informação pode permanecer para sempre e, além dos dados já armazenados, novas informações poderão ser permanentemente acrescentadas, das quais dificilmente o indivíduo se livrará. Isso significa que as redes, ao mesmo tempo em que ampliam as relações, são também poderosos instrumentos de controle.

Nesse controle globalizado, onde tais dispositivos são massivamente visibilizados na abundância de imagens, é que funcionam os processos de subjetivação - tornando as evidências necessárias, naturais e palatáveis de forma incessante e, paradoxalmente, em um invisível-não-escondido. Modos de existência que, ao mesmo tempo, são aprisionantes e aprisionadores.

Segundo Deleuze (1992), em seu texto "Postscriptum sobre as sociedades de controle":

Até a arte abandonou os espaços fechados para entrar nos circuitos abertos do banco [...] o marketing é agora o instrumento de controle social e forma a raça impudente de nossos senhores.
O controle é de curto prazo e de rotação rápida, mas também contínuo e ilimitado (p. 224).

Um controle a céu aberto, no qual celas, grades e muros, aparentemente invisíveis, potencializam ao máximo as lógicas da informática e do ciberespaço, impregnando esses processos de subjetivação em nossas práticas diárias de vida.

\section{I nformática, controle e o dispositivo das redes}

\begin{abstract}
A idéia é pensar o dispositivo das redes tanto subjetivas quanto sociológicas e tecnológicas, mas com foco aguçado para as de comunicação e informação, cujos sistemas vêm suscitando ao mesmo tempo rejeição e fascínio. Tecnologias políticas de controle e de produção de subjetividade que vêm afirmando uma racionalidade individualista e massificante ainda que se apresente como um campo potencialmente revolucionário, permeado de processualidade e de abertura a novos mundos (MOREIRA, 2006, p. 93).
\end{abstract}

Norbert Weiner, em seu clássico livro “Cibernética e sociedade" (1970), afirma que se viu forçado a criar uma palavra específica, ao tentar designar, em 1950, o complexo de idéias que envolvia as novas tecnologias nascentes, relacionadas com a transmissão de mensagens, o desenvolvimento das máquinas computadoras, os autômatos e "as reflexões a cerca da psicologia e do sistema nervoso e uma nova teoria conjectural do método cientifico" (p. 15). Ao apresentar esse novo termo, diz: "Daí Cibernética que derivei da palavra grega kubernetes, ou piloto, a mesma palavra grega de que eventualmente derivamos a palavra governador" (WEINER, 1970, p. 15).

Assim, desde sua etimologia, esse complexo de tecnologias, dentre elas a informática e a produção de redes, está intrinsecamente ligado à idéia de governo, de controle. Não por acaso, elas emergem e se fortalecem no momento em que se dá a flexibilização do capital e a sociedade de controle se insinua e se globaliza. Um processo que tem seu começo na década de 1940.

No período da segunda guerra mundial surge o primeiro computador que, segundo Pierre Levy (1993), pesava várias toneladas e ocupava um andar inteiro de um prédio. Foi depois programado por códigos binários em fitas perfuradas. Na década de 1960, ficou famoso o primeiro computador eletrônico da Pontifícia 
Universidade Católica do Rio de Janeiro (PUCRJ), instalado em quase todo térreo do prédio de pilotis. Novas linguagens surgiram e, mais adiante, as telas e, finalmente, os computadores pessoais. Neste período, os serviços de inteligência americanos foram os primeiros a usar a internet, as redes eletrônicas de comunicação, como máquinas de informações sigilosas de controle político interno e principalmente externo.

Dia após dia inventam-se novas linguagens, o que significa que o poder de armazenamento e velocidade das informações parece infinito, o que nos transforma em velocistas exauridos na maratona infindável atrás de novas tecnologias. Nada é estável na tecnologia da informática, no entanto grande parte do conteúdo que se espalha pelo ciberespaço é extremamente conservador. Portanto, apesar de toda instabilidade, não estamos muito longe do mundo platônico da imutabilidade das idéias que, embora múltiplas, são idênticas em si mesmas, e hoje substituem massivamente o pensamento pela informação.

Mas, outros efeitos são inegáveis. A cibernética, que estuda as comunicações e o sistema de controle dos organismos e das máquinas, trouxe inovações tecnocientíficas inimagináveis para a análise de processos físicos, fisiológicos e psicológicos de transformação da informação.

O computador está fornecendo a comunicação e a organização para se administrar a informação genética que compõe a economia biotecnológica. No mundo todo, pesquisadores estão usando computadores para decifrar, trocar, catalogar e organizar a informação genética, criando um novo estoque de capital genético para ser usado na era bioindustrial. As tecnologias de computação e as genéticas estão se fundindo numa nova e poderosa realidade tecnológica (RIFKIN, 1999, p. 9-10).
A esse respeito, o mesmo autor menciona o nascimento de uma nova eugenia ${ }^{3}$, novos homens e mulheres eugênicos, uma raça de humanos superiores, não mais um ideal fundado por Francis Galton no século XIX e que teve aplicação em várias partes do mundo durante o século $X X$, principalmente nos Estados Unidos ${ }^{4}$, culminando no nazismo na Alemanha, e de grande repercussão no Brasil ${ }^{5}$, de forma a constituir o que Foucault (2000) chama de "racismo de Estado". Hoje, já não é mais "[...] um sonho de demagogos desvairados, mas uma opção de consumo, em breve disponível, e um mercado comercial potencialmente lucrativo" (RIFKIN, 1999, p. 122). Essa nova eugenia não pode ser necessariamente comparada ao holocausto nazista, primeiro porque dispõe de ferramentas científicas para manipular as instruções genéticas nas terapias somáticas ${ }^{6}$ antes inexistentes, e segundo porque vem mascarada por uma biopolítica de beneficio social. Contudo, isto não quer dizer que estamos próximos da universalização do bem estar social mas, ao contrário, no limiar de novas formas de exclusão pela via do desenvolvimento dessa nova eugenia.

Em 1975-1976, em seu curso “Em defesa da sociedade", Michel Foucault ao formular uma história do presente que caracteriza a sua obra filosófica, já apontava para o abuso da biotecnologia:

Esse excesso do biopoder aparece quando a possibilidade é técnica e politicamente dada ao homem, não só de organizar a vida, mas de fazer a vida proliferar, de fabricar algo vivo, de fabricar algo monstruoso - no limite - vírus incontroláveis e universalmente destruidores. Extensão formidável do biopoder que [...] vai ultrapassar a soberania humana (FOUCAULT, 2000, p. 303).

Sobre aquele "excesso de biopoder" ao qual Foucault se referia, cerca de vinte anos depois, Rifkin nos alerta:

\footnotetext{
${ }^{3} \mathrm{O}$ termo eugenia costuma ser dividido em dois aspectos. A eugenia negativa que se constitui na eliminação de traços biológicos e comportamentais indesejáveis (a esterilização, como aconteceu em vários países no início do século XX, além do extermínio nazista), e a conseqüente eugenia positiva, que trata da reprodução seletiva, pela exigência de certificados médicos obrigatórios para os casamentos e os cruzamentos de espécimes puros da raça com a finalidade de "aprimorar" a espécie.

${ }^{4}$ De tal maneira a eugenia desenvolveu-se nos Estados Unidos que, em 1925, “[...] oficiais alemães escreviam aos governos estaduais norte-americanos a respeito de sua legislação sobre a esterilização" (RIFKIN, 1999, p. 133). A filosofia eugênica só arrefeceu com a queda da bolsa de valores de 1929, quando muitos membros da chamada elite norte-americana (os chamados WASP: brancos, anglo-saxões, protestantes) cometeram o suicídio ou entraram na fila dos desempregados e da sopa para os pobres.

${ }^{5}$ Ver Lobo (2001).

${ }^{6}$ As manipulações genéticas podem ser de dois tipos: “No tratamento somático, a intervenção ocorre em células somáticas e as alterações genéticas não se transferem para os descendentes. Na terapia de linha germinativa, as alterações genéticas são efetuadas no esperma, ovo ou células embrionárias e são passadas às próximas gerações" (RIFKIN, 1999, p. 135).
} 
Muitos cientistas na linha de frente da revolução da tecnologia do computador estão convencidos de que a informação é a chave para a imortalidade. Yoneji Masuda [...] escreve entusiasticamente a respeito do seu mais recente veículo para a imortalidade terrestre: 'Ao contrário dos bens materiais a informação não desaparece ao ser consumida, e, até mais importante, o valor da informação pode ser ampliado indefinidamente através de constantes adições de nova informação à já existente. Assim, as pessoas vão continuar a utilizar a informação que elas e outros criaram até mesmo após ter sido usada. Argumenta-se que a informação não é facilmente atingível pela destruição causada pelo tempo. Ela é desse mundo, mas não morre com a carne (RIFKIN, 1999, p. 228).

A rede pode ser uma técnica especial para o controle. Ao mesmo tempo em que estendem as relações produz controle. O que nos espera? Essa imortalidade da informação significa que as marcas ou os rótulos ficarão cunhados para sempre e não têm possibilidade de um dia desaparecerem? Estaremos todos, de geração em geração, marcados eternamente como num céu de Platão?

\section{Uma ética da informática para os amplos sentidos da educação na contemporaneidade}

O filósofo do futuro é ao mesmo tempo o explorador dos velhos mundos, cumes e cavernas, e só cria à força de se lembrar de qualquer coisa que foi essencialmente esquecida. Esta qualquer coisa, segundo Nietzsche, é a unidade do pensamento e da vida. Unidade complexa: um passo para a vida, um passo para o pensamento. Os modos de vida inspiram maneiras de pensar, os modos de pensar criam maneiras de viver. A vida ativa o pensamento e o pensamento, por seu lado, afirma a vida (DELEUZE, 1985, p. 17).

Dentre as várias possibilidades de utilização das tecnologias de informatização, das redes e dos bancos de dados, pensamos debater aqui as utilizadas na área da educação hoje, tomando-a em seus amplos sentidos, como um processo que percorre todo o tempo da vida humana, não se restringindo apenas à instituição escola.

São inegáveis as facilidades trazidas por essas novas tecnologias no que se refere tanto à saúde - com o advento das pesquisas de células tronco, por exemplo, apontando brevemente para cura de doenças tidas hoje como incuráveis - como quanto à educação, pela rapidez com que se coletam e processam informações. No entanto, é preciso destacar que a velocidade desta coleta não constrói conhecimento, apenas se reduz a um amontoado de colagens fornecidas pela internet. Uma tal concepção vem sendo caracterizada como "democratização do acesso à informação", como se tudo aquilo que está lá, pronto, são dados simplesmente aguardando para serem colhidos, ao alcance de todos, infensos ao ataque de outras intenções. Tudo muito isento, neutro e objetivo. A facilidade com que se trocam informações e a instantaneidade dos sistemas de comunicação instauram em nós tais evidências naturalizadas. Foucault (pesquisar na rede $\mathrm{O}$ sujeito e o poder) nos alerta para o fato de que, embora seja necessário distinguir relações de comunicação das relações de poder, isto não significa que ambas estejam em domínios separados:

Trata-se de [...] tipos de relação que, de fato, estão sempre imbricados uns aos outros e servindo-se mutuamente de instrumento. [...] Quanto às relações de poder propriamente ditas, elas se exercem por um aspecto extremamente importante através da produção da troca de signos. [...] Seja, por exemplo, uma instituição escolar: sua organização espacial, o regulamento minucioso que rege sua vida interior, as diferentes atividades aí organizadas, os diversos personagens que aí vivem e se encontram [...] - tudo isso constitui um 'bloco' de capacidade-comunicação e poder (FOUCAULT, 1995, p. 241).

Além disso, todo o processo de aquisição de informação implica sempre em escolhas, daí, no turbilhão veloz de signos que comprimem tempo e espaço no nosso mundo, a necessidade urgente de critérios para essa seleção. Trata-se de um problema ético da maior importância; uma crítica que precisa atravessar todos os nossos atos cotidianos, onde quer que estejamos. O trabalho do educador, por exemplo, não se resume somente em ensinar o uso das máquinas, seus segredos e técnicas, mas principalmente, submeter

[...] as máquinas ao nosso poder e desejo de inventar novos jogos ainda não revelados na prática. Trata-se, portanto, de criarmos por meio da educação modos de confronto com a experiência tecnológica, colocando tanto educadores quanto educandos na posição de se sentirem responsáveis por inventar outras estratégias de interação na produção do conhecimento (SOUZA, [entre 2001 e 2007]). 
Entendemos, como Foucault (1996), que o conhecimento, “[...] é luta, é combate [...] além de não derivar da natureza humana, nem mesmo é aparentado [...] com o mundo a conhecer" ( p. 17).

Logo, se o conhecimento ele próprio é uma invenção, nada tem a ver com a compreensão das coisas, nem com o reconhecimento e muito menos com a necessidade de identificá-las ou identificar-se com elas. Não se trata nem de apaziguamento, nem de continuidade com as coisas. Por isso, toda neutralidade é impossível no ato de conhecer.

Sabe-se que, de um modo geral, os educadores estão sendo arrastados por um irresistível poder de sedução, falando entusiasticamente "da democratização do acesso à informação", como sinônimo de produção de conhecimento. Dessa forma, não se pensa, apenas copia-se e reconhece-se segundo o mundo das cópias de Platão.

Segundo Alphen (2008) a utilização dessas novas tecnologias torna-se simples reprodução acrítica:

[...] porque tudo está aí, muito barato e principalmente mastigado. É só entrar na internet [...] Antes a gente era mais desconfiado, ficava cabreiro e ia atrás das fontes. Hoje, já que sabemos que somos agentes poderosíssimos de mudança, sozinhos, 'só eu com minha internet', porque quebrar a cabeça atrás de fatos e fontes? Mais do que nunca, agora, se dá melhor quem melhor e mais rápido se expressa, e não quem melhor pesquisa e pensa. No limite, o acesso livre à informação pode ser um soporífero intelectual (p. 7).

Alardeia-se, com particular orgulho na nossa chamada "pós-modernidade", a transformação do receptor em emissor e vice-versa, como se fosse esta a tradução mais fiel da interatividade, uma atividade não centrada no emissor. Porém, em raros espaços a rede da internet pode ser considerada rizomática ${ }^{7}$, como o caso de alguns chats. Ela é na verdade centralizada por um provedor, invadida por hackers clandestinos ou oficiais, pela propaganda, pelos spams. Como desenvolver na educação uma ética da autonomia e não da chamada intera- tividade, um novo eufemismo para mascarar o controle dos vetores de subjetivação? Respondendo a certas palavras de ordem embutidas no marketing não estamos sendo levados a acreditar que somos participantes ativos? E, dessa forma, não estaremos também fortalecendo a atitude passiva diante de tudo que nos é "democraticamente" imposto?

A esse respeito Naomi Klein (2004) nos relata, dentre outros, um caso exemplar de marketing em muitas escolas públicas norteamericanas, onde a retirada de recursos do Estado tem se tornado flagrante:

[...] a rede de computadores nas escolas ZapMe! não apenas vende espaço publicitário a seus patrocinadores; ela também monitora os caminhos que os estudantes percorrem quando navegam na net e fornece sua valiosa pesquisa de mercado, subdividida por sexo, idade, código postal dos estudantes para seus publicitários. Assim, quando os estudantes se conectam com a ZapMe! eles são expostos às propagandas que foram especialmente 'microdirigidas' a eles. Esse grupo de pesquisa detalhada de mercado está explodindo nas escolas da América do Norte: grupos de pesquisas semanais, testes de preferências, pesquisas de opinião, discussões na internet, todos estão sendo usados atualmente dentro das salas de aula. [...] Ao explicar os méritos de um teste de sabor de um cereal matinal, o diretor da escola elementar Our Lady Assumption, Massachusetts, disse: 'É uma experiência de aprendizagem. Eles têm de ler, têm de observar, têm de comparar.' (p. 118, grifos nossos).

A se levar em conta que se trata de país desenvolvido, geralmente citado como modelo na área tecnológica (vide a Microsoft), e que se auto-intitula "paladino da democracia mundial", será este também o modelo de interatividade que nos aguarda? Uma coisa é a preocupação do governo brasileiro em usar a tecnologia no sistema educacional, alardeando a inclusão digital na formação de professores, e levar a informática para as escolas públicas. Outra coisa é o feitichismo da técnica e o seu uso para o controle da população - em especial a jovem - para os lucros do capital.

Além disso, não faria mal um olhar crítico para os objetivos apregoados pelos chamados

\footnotetext{
7 Rizoma é um conceito formulado por Deleuze e Guattari (1980), para um “método" de pensar as questões da linguagem, da comunicação, e da própria filosofia que segue um movimento transversal de conexões inteiramente descentradas, nem ao menos policentradas. Utilizando uma classificação da botânica para um tipo de vegetação cujo crescimento se espalha sem uma raiz central, uma ramificação em todos os sentidos sem uma direção determinada até sua concreção em bulbos ou tubérculos, os autores opõem o rizoma à forma arborescente de instaurar cadeias que crescem a partir de uma raiz central, e seguem direções pré-estabelecidas. Trata-se aqui de um conceito-ferramenta para avaliação das chamadas redes da internet.
} 
projetos político-pedagógicos. Tais discursos, em sua maioria, são apenas aparentemente afirmativos: defendem o desenvolvimento das "potencialidades", das "competências", das "habilidades". Na verdade, o sucesso da política educacional brasileira repousa num subentendido filantrópico, intrinsecamente negativo, dirigido para as populações de baixa renda, seja no sistema público ou no privado das chamadas ONGs: o governo das crianças pobres pela prevenção do perigo social que representam, através do lema sempre repetido: "lugar de criança é na escola, não nas ruas" ou "mentes vazias, oficinas do diabo". Este discurso filantrópico, que no início do século $X X$, aliou-se ao higienismo médico, hoje acha-se de mãos dadas com a informática.

Por isso, mais do que nunca, necessitamos de uma ética afirmativa que se contraponha, como via de escape, à moral negativa da filantropia, ao assistencialismo e à punibilidade tão arraigados em nossas subjetividades contemporâneas; enfim, de tudo que torna a vida insuportável. Uma ética positiva do “governo de si e dos outros" (FOUCAULT, 2008), uma preocupação permanente com a invenção de si, construída ao largo da exploração e do poder do capital. Uma ética que, diferentemente da moral, afirma encontros e relações potentes, conjurando as penas e as sanções, não se apoiando em princípios transcendentes ou universais. Uma ética que ultrapassa as relações de poder, propondo no lugar das coerções as "regras facultativas", que instauram a "existência como obra de arte" (DELEUZE, 1992).

A questão que se coloca é que, se não estamos afirmando uma essência para essas novas tecnologias, não podemos conjurá-las como maléficas em si mesmas. O problema ético continua e mais do que nunca precisa ser debatido coletivamente.

\footnotetext{
Não se deve perguntar qual o regime mais duro ou o mais tolerável, pois é em cada um deles que se enfrentam as liberações e as sujeições [...]. [Portanto], não cabe temer ou esperar, mas buscar novas armas (DELEUZE, 1992, p. 220).
}

\section{Referências}

ALPHEN, F. Internet: droga e ilusão. J ornal O Globo, São Paulo, 09 set. 2008. Opinião.

DELEUZE, G. Nietzsche. Lisboa: Edições 70, 1985.

DELEUZE, G. Conversações. Rio de Janeiro: Escuta, 1992.

DELEUZE, G.; GUATTARI, F. Mille plateaux: capitalisme et schizophrénie. Paris: Les Éditions de Minuit, 1980.

FOUCAULT, M. Vigiar e punir: nascimento da prisão. Petrópolis:Vozes, 1986.

FOUCAULT, M. O sujeito e o poder In: DREYFUS, H. L.; RABINOW, P. Michel Foucault. Uma trajetória filosófica: para além do estruturalismo e da hermenêutica. Rio de Janeiro: Florence Universitária, 1995. p. 231-249.

FOUCAULT, M. A verdade e as formas jurídicas. Rio de Janeiro: NAU, 1996.

FOUCAULT, M. Em defesa da sociedade. São Paulo: Martins Fontes, 2000.

FOUCAULT, M. Le gouvernemment de soi et des autres. Cours au Collège de France, 1982-1983. Paris: Gallimard, 2008.

HARVEY, D. A condição pós-moderna. São Paulo: Loyolla, 1993. 
JARDIM, L. França ficha jovens para identificar “futuros delinqüentes". In: Terra. Notícias. [S.I.: s.n.], 13 jun. 2008. Disponível em: <http://noticias.terra.com.br/mundo/interna/0,,Ol3006465-El8142,00.html>. Acesso em: 13 jul. 2008.

KLEIN, N. A tirania das marcas em um planeta vendido. Rio de Janeiro: Record, 2004.

LEVY, P. As tecnologias da inteligência. Rio de Janeiro: Ed. 34, 1993.

LOBO, L. F. Movimento Eugênico: tribunal de todos os desvios. In: JACÓ-VILELA, A. M.; CEREZZO, A. C.; RODRIGUES, H. B. C. (Orgs.). Clio-psyché ontem: fazeres e dizeres psi na história do Brasil. Rio de Janeiro: Relume Dumará, 2001.

MARTINS, M. C.; FERRERI, M. A. Infância, cidadania e paradoxos: entre lutas e políticas. In: MENDONÇA FILHO, M. (Org.). Educação, violência e polícia: direitos humanos? Aracajú: EDUFBA, 2004. p. 195-225.

MOREIRA, F. H. O biopoder e suas tecnologias políticas: uma análise dos processos de produção da identidade delinqüente. 2006. Dissertação (Mestrado em Psicologia)- Universidade Federal Fluminense, Niterói, 2006.

RAGO, M. Do cabaré ao lar: a utopia da cidade disciplinar - Brasil 1890-1930. Rio de Janeiro: Paz e Terra, 1987.

RIFKIN, J. O século da biotecnologia: a valorização dos genes e a reconstrução do mundo. São Paulo: Makron Books, 1999.

RODRIGUES, R. C. O estado penal e a sociedade de controle: o programa delegacia legal como dispositivo de análise. 2008. Dissertação (Mestrado em Psicologia)- Universidade Federal Fluminense, Niterói, 2008.

ROLNIK, S. Subjetividade antropofágica. In: BIENAL INTERNACIONAL DE SÃO PAULO. Catálogo da XXIV Bienal Internacional de São Paulo. São Paulo, 1998.

SIBILIA, P. O homem pós-orgânico: corpo, subjetividade e tecnologias digitais. Rio de Janeiro: Relume Dumará, 2002.

SOUZA, S. J. A criança na Idade Média: desafios para a formação do educador. In: MULTIRIO - EMPRESA MUNICIPAL DE MULTIMEIOS DA PREFEITURA DO RIO DE JANEIRO. Rio Mídia. Notícias. Rio de Janeiro, [entre 2001 e 2007]. Disponível em: <http://www.Multirio.rj.gov.br/RIOMIDI A/Noticia/por_51_1.asp>. Acesso em: 22 set. 2008.

WACQUANT, L. A ascensão do Estado penal nos EUA. Discursos sediciosos: crime, Direito e sociedade. Rio de Janeiro, v. 7, n. 11, 2002, p. 13-39.

WEINER, N. Cibernética e sociedade: o uso humano de seres humanos. São Paulo: Cultrix, 1970.

Recebido em março de 2008

Aceito para publicação em maio de 2008 


\section{Maria Lívia do Nascimento}

Doutora em Psicologia Social pela Pontifícia Universidade Católica de São Paulo (PUC-SP). Pós-doutora pela Université de Paris VIII. Professor adjunto 4 da Universidade Federal Fluminense (UFF).

ppgpsicologia@hotmail.com

\section{Lilia Lobo}

Doutora em Psicologia pela Pontifícia Universidade Católica do Rio de Janeiro (PUC-RJ). Professor adjunto da UFF. ppgpsicologia@hotmail.com

\section{Cecília Maria Bouças Coimbra}

Doutora em Psicologia Escolar e do Desenvolvimento Humano e pós-doutora pela Universidade de São Paulo (USP). Professor adjunto 4 da UFF.

ppgpsicologia@hotmail.com 